\title{
The Correlation between Excess Weight and Duration of COVID-19 Symptoms in a Tertiary Hospital in Amman, Jordan
}

\author{
Laith Khasawneh $^{*}$, Duaa Shaout, Sara Abu-Ghazal, Tishreen Fazza and Mohammad \\ Abdelmajid
}

Department of Surgery, Faculty of Medicine, Hashemite University

Received: Dec 13, 2020; Revised: Jan 25, 2020; Accepted: Feb 2, 2021

\begin{abstract}
Overweight and obesity have several negative pathophysiological consequences on the human body during COVID-19 infection. These pathophysiological consequences have a synergistic effect on disease prognosis and outcome. The association between excess weight and COVID-19 outcome has not been investigated before in Jordan. The objective of this study is to evaluate the correlation between excess body weight and the duration and severity of symptoms in patients affected by the novel corona virus in a tertiary hospital in Amman, Jordan. This is a single-center retrospective cross-sectional study of adult patients with confirmed positive COVID-19 who were admitted to a tertiary academic hospital between April and August 2020. Data were collected by telephone interviews and by the review of medical records. One hundred and seventy patients participated in the current study. Around two-thirds of the participants were female patients. Mean BMI for study participants was $27.6 \pm 5.4$. BMI was statistically significantly correlated with COVID-19 symptoms duration ( $p$-value $=0.003$ ). The mean duration of COVID-19 symptoms for obese patients was $16.0 \pm 7.3$ days compared to a mean duration of $11.9 \pm 6.4$ days for overweight patients and a mean duration of $12.0 \pm 6.1$ days for patients with normal BMI. Multivariate analysis showed that higher BMI was significantly associated with increased symptom duration after controlling other variables. There is a need to increase public health efforts in fighting overweight and obesity. The Jordanian authorities are advised to develop focused awareness messages for overweight and obese individuals to have strict social distancing and other prevention measures against COVID-19. People with increased BMI are a vulnerable group for this respiratory infection and they deserve advanced and tailored efforts to protect them from its adverse outcomes.
\end{abstract}

Keywords: COVID-19, SARS-COV-2, Body Mass Index, Excess weight

\section{Introduction}

The new coronavirus (2019-nCov) infection, which is thought to have a zoonotic origin, appeared first in the Chinese province of Wuhan back in December 2019 (Cornejo-Pareja et al., 2020; Curtin et al., 2020). In 2020, towards the end of the first quarter, the World Health Organization (WHO) declared an emergency state: the virus had become a global pandemic (Cuthbertson et al., 2020). Affecting over 216 countries or territories by August 2020, with around 20 million infected cases, the death toll has reached over 700 thousand deaths (Huang et al., 2020). The first case of COVID-19 was reported in Jordan on March 2, 2020 (Samrah et al., 2020b). By July 2020, the total number of active cases in Jordan reached 1,209 and 10 confirmed deaths have been reported (Akour et al., 2020).

Overweight and obesity are major health challenges, as they might raise the risk of other diseases considerably. With prevalence stages on the steady increase globally for almost half a century, it has reached a pandemic level, thus contributing to a deterioration in individuals' quality of life and longevity (Blüher, 2019). Previous estimates showed that more than two billion people are overweight globally and more than 650 million people are obese (Khan and Moverley Smith, 2020; Magdy Beshbishy et al., 2020). In Jordan, obesity rates have been in constant increase. It has been reported as being among the highest in the region. A recent study estimated that three-quarters of Jordanian adults suffer from obesity or overweight according to their body mass index (BMI) measurement (Ajlouni et al., 2020). BMI is a widely used, low-cost tool to assess patients' weight status. It is a useful predictor for poor health outcomes in overweight and obese patients (Hall and Cole, 2006; Klatsky et al., 2017).

The first suspicions about the association between poor COVID-19 outcomes and obesity came from China in April 2020 (Dyett, 2020). However, obesity prevalence in China is in general lower than in western countries. Therefore, this association was not fully observed until the pandemic reached western hemisphere countries that suffer from higher obesity prevalence, such as the USA, Spain, Italy and other developed countries (Holly et al., 2020; Kwok et al., 2020; Rancourt et al., 2020). Although age remains the most single independent risk factor for poor COVID-19 prognosis (Lockhart and O'Rahilly, 2020), the current literature identified overweight and obesity as another strong independent and significant risk factor for COVID-19 mortality, Intensive Care Unit (ICU)

\footnotetext{
* Corresponding author e-mail: L.Khasawneh80@gmail.com.
} 
admission, intubation for mechanical ventilation, and other severity or poor prognosis indicators (Caussy et al., 2020; Huang et al., 2020; Liu et al., 2020; Smati et al., 2020).

Overweight and obesity have several negative pathophysiological consequences on the human body during COVID-19 infection. These pathophysiological consequences have a synergistic effect on disease prognosis and outcome (Caci et al., 2020; Kimura and Namkoong, 2020). For example, Fedele et al. and Holly et al. reported that obese COVID-19 patients tend to have hyper- coagulopathy status and inadequate immune response. Besides, overweight has been linked to specific co-morbidities that are very concerning, such as hypertension, type 2 diabetes mellitus, coronary artery diseases, sleep apnea among others (Fedele et al., 2021; Holly et al., 2020; Magdy Beshbishy et al., 2020; Popkin et al., 2020).

Adipose tissue was identified as a reservoir for SARSCoV-2 virus (Kruglikov et al., 2020; Ranjan et al., 2020). It also creates a microenvironment with several hormonal and metabolic effects that worsen the infection. Excessive fat tissue was linked with the upregulation of AngiotensinConverting Enzyme 2 (ACEII) receptors, which are used by the SARS-CoV-2 virus to infect host cells at several organs (Kang et al., 2020; Magdy Beshbishy et al., 2020). Moreover, the low inflammatory status of the obese body could lead to cytokine storm, elevated interleukin levels and, eventually, excessive inflammatory response after COVID-19 infection (Biscarini et al., 2020; Seidu et al., 2020; Soeroto et al., 2020). It is well-known that adipose tissue secretes leptin and adiponectin and those two hormones play a major pro-inflammatory and antiinflammatory roles (Gunturiz Albarracín and Forero Torres, 2020). However, what has been discovered recently is the association between COVID-19 complications and inflammatory effects of leptin and adiponectin (Méry et al., 2020). Another possible explanation for poor COVID-19 infection outcomes in obese and overweight patients is the mechanical consequences of excessive fat tissue on the respiratory system (Curtin et al., 2020). Visceral fat limits diaphragmatic movement, especially in the prone position. Also, obesity decreases the expiratory reserve volume of the lungs, affects the pulmonary perfusion, increase the chances for lung fibrosis and excise neck fat tissue affects the intubation process (Kwok et al., 2020; Malik et al., 2020; Soeroto et al., 2020).

Unfortunately, the lockdown measures that aimed to flatten the curve have led to not only negative economic consequences but also it was associated with reports about extra food consumption, very limited exercises opportunities, stress-related eating disorders and all of these behaviors would eventually increase the risk for overweight, which would deteriorate COVID-19 management efforts (Cornejo-Pareja et al., 2020; Khan and Moverley Smith, 2020; Singh et al., 2020). This association between obesity and poor respiratory infection outcome has been observed before during the H1N1 epidemic, and it is a recurrent observation with seasonal flu, among other viral pneumonia infections (Michalakis et al., 2020; Shaka et al., 2020).

To the best of our knowledge, the association between overweight and COVID-19 outcome has not been investigated before in Jordan and there is only one published article that examined this association on patients from Arab ethnicity (Al-Sabah et al., 2020). The objective of the current study was to evaluate the correlation between excess weight and the duration and severity of symptoms in patients affected by the novel corona virus in a tertiary hospital in Amman, Jordan.

\section{Materials And Methods}

This is a single-center retrospective cross-sectional study of patients with confirmed positive COVID-19 diagnosis, who were admitted to a tertiary academic hospital between April and August 2020. At the time of data collection, all patients in Jordan with COVID-19 positive tests were under mandatory hospital quarantine regardless if they were symptomatic or asymptomatic (Samrah et al., 2020a).

A convenience sample of admitted COVID-19 cases was selected. Data were collected through reviewing patients' records and by a short telephone interview. All telephone interviews were conducted in July and August 2020. This study was reviewed and approved by the Hashemite University Institutional Review Board (IRB). After explaining the study purpose and details, verbal consent was obtained from all study participants during the telephone interview. For data protection purposes, all collected data in this study were de-identified data.

Inclusion criteria were any adult patient (18+ years old) with confirmed COVID-19 PCR test who was admitted to Prince Hamza Hospital. Included cases were diagnosed with SARS-CoV-2 infection based on the World Health Organization's interim guidance (Ravi et al., 2020). The confirmation of SARS-CoV-2 infection was done by RealTime Polymerase Chain Reaction (RT-PCR) assay using a nasal or a pharyngeal swab. Exclusion criteria were patients without a confirmed test, patients with missing anthropometric measurement data at the medical record and pregnant women.

The dependent variables of this study were the duration of symptoms, defined here as those patients complaining of any coronavirus associated symptoms and ICU admission.

Several covariates of interest were collected in the current study, such as age, sex, weight, height, and comorbidities. BMI was calculated in kilograms per meter squared on admission through standardized measurements of weight and height. The patient was considered overweight when the BMI result was between 25 and 29.9 and considered obese when the BMI was 30 or more (Hijona Elósegui et al., 2020). Comorbidities were identified if the patient had a medical record with an established diagnosis, or was on medications known to treat these comorbidities.

\section{Statistical Analysis}

Means and Standard Deviation (SD) were calculated for age and BMI. Categorical patient characteristics were summarized with counts and percentages. Pearson correlation was used to measure the correlation between study variables. Multivariable logistic regression analysis was performed to examine the association between ICU Admission adjusting for the potential effects of BMI, age, sex and comorbidities. Results were presented as odds 
ratios (OR) with 95\% confidence intervals (C.I.s). A pvalue of less than 0.05 was considered statistically significant. Data were analyzed using Statistical Package for Social Science (SPSS) software (IBM Corp. Released 2017. IBM SPSS Statistics for Windows, Version 25.0. Armonk, NY: IBM Corp).

\section{Results}

One hundred and seventy patients participated in the current study. Around two-thirds of the participants were female patients. The mean age of study participants was $41.8 \pm 14.4$ years. The main characteristics of the included COVID-19 participants are described in Table 1. Around one-quarter of the participants had one or more non- communicable diseases (NCDs). The most frequent reported NDCs were type 2 Diabetes mellitus (DM) and hypertension, $11.8 \%$ and $7.6 \%$, respectively (Table 1 ).

Mean BMI for study participants was $27.6 \pm 5.4$. Six out of ten patients were either overweight or obese. The prevalence of overweight between hospitalized COVID-19 patients was $34.1 \%$ and the prevalence of obesity was $29.4 \%$. Only $4.1 \%$ of the participants required ICU admission for COVID-19 management (Table 1).

Around half of the participants were symptomatic (56.5\%). The symptoms lasted for almost two weeks (mean $13.1 \pm 6.8$ days). The three most common reported symptoms were cough, loss of smell and loss of taste, $25.9 \%$, 31.8\%, and 25.9\%, respectively (Table 1 ).

Table 1 Characteristics of included COVID-19 cases ( $\mathrm{n}=170$ )

\begin{tabular}{|c|c|c|}
\hline Variable & Number & Percent \\
\hline \multicolumn{3}{|c|}{ Age (years) (mean $\pm \mathrm{SD}=41.8 \pm 14.4)$ range $(18-83)$} \\
\hline \multicolumn{3}{|l|}{ Sex } \\
\hline Male & 58 & 34.1 \\
\hline Female & 112 & 65.9 \\
\hline \multicolumn{3}{|l|}{ Comorbidities } \\
\hline Type 2 DM & 20 & 11.8 \\
\hline Hypertension & 13 & 7.6 \\
\hline Other comorbidities & 12 & 8.1 \\
\hline \multicolumn{3}{|l|}{ On chronic medications } \\
\hline No & 136 & 80.0 \\
\hline Yes & 34 & 20.0 \\
\hline \multicolumn{3}{|l|}{ Received seasonal flu vaccine in 2019} \\
\hline No & 157 & 92.4 \\
\hline Yes & 13 & 7.6 \\
\hline \multicolumn{3}{|c|}{ BMI (mean $\pm \mathrm{SD}=27.6 \pm 5.4)$ range $(17.6-45.5)$} \\
\hline Underweight $(<18.5)$ & 3 & 1.8 \\
\hline Normal (18.5-24.9) & 59 & 34.7 \\
\hline Overweight $(25.0-29.9)$ & 58 & 34.1 \\
\hline Obese $(\geq 30.0)$ & 50 & 29.4 \\
\hline \multicolumn{3}{|c|}{ Requiring ICU admission for COVID-19 management } \\
\hline No & 163 & 95.9 \\
\hline Yes & 7 & 4.1 \\
\hline Treated with an Oxygen mask & 13 & 7.6 \\
\hline Treated with Hydroxychloroquine & 81 & 47.6 \\
\hline \multicolumn{3}{|l|}{ Symptomatic } \\
\hline No & 74 & 43.5 \\
\hline Yes & 96 & 56.5 \\
\hline \multicolumn{3}{|l|}{ Reported symptoms* } \\
\hline Cough & 44 & 25.9 \\
\hline Shortness of breath & 24 & 14.1 \\
\hline Fever & 46 & 27.1 \\
\hline General weakness & 32 & 18.8 \\
\hline Loss of smell & 54 & 31.8 \\
\hline Loss of taste & 44 & 25.9 \\
\hline Headache & 21 & 12.4 \\
\hline Gastrointestinal symptoms & 23 & 13.5 \\
\hline Flu like symptoms & 12 & 7.1 \\
\hline
\end{tabular}

Symptoms duration (days) ( $\mathrm{n}=96)$ (mean $\pm \mathrm{SD}=13.1 \pm 6.8$ )

* Percentages do not add up to $100 \%$ due to multiple symptoms. 
On correlation analysis, BMI was statistically significantly correlated with COVID-19 symptoms duration ( $\mathrm{p}$-value $=0.003)$. Similarly, a significant correlation was identified between symptoms duration and ICU admission (p-value $<0.001$ ), and a significant

Table 2. Correlation of study variable with Symptoms Duration ( $\mathrm{n}=96)$

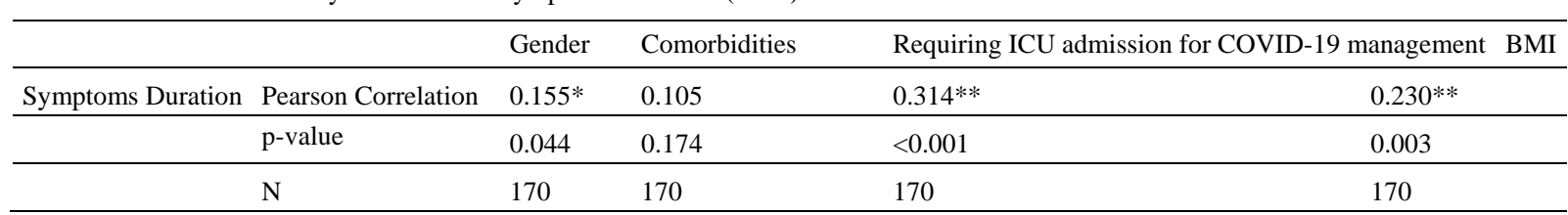

* Correlation is significant at the 0.05 level (2-tailed).

** Correlation is significant at the 0.01 level (2-tailed).

Meanwhile, multivariate analysis was used to examine the adjusted effect of the study variable on ICU admission. The only variable that was a significantly associated factor with ICU admission was the age of $60+$ years, after controlling for other variables (odds ratio 9.0, 95\% C.I. 1.5 - 55.9) (Table 3).

Table 3. Adjusted Odd Ratio of Study Variables on ICU Admission for COVID-19 Management in Logistic Regression Analysis $(\mathrm{n}=170)^{*}$

\begin{tabular}{llll}
\hline Variable & Adjusted OR & 95\% C.I. & p-value \\
\hline Age & & & \\
\hline $60+$ years & 9.0 & $(1.5-55.9)$ & $0.018^{*}$ \\
\hline$<60$ years & Reference & - & \\
\hline Gender & & & \\
\hline Male & 1.0 & $(0.2-5.6)$ & 0.978 \\
Female & Reference & - & \\
\hline Comorbidity & & & 0.613 \\
\hline Yes & 1.6 & $(0.3-9.8)$ & \\
\hline No & Reference & - & \\
\hline$*$ Significant $a<0.05$ level & &
\end{tabular}

* Significant at $\alpha<0.05$ level

\section{Discussions}

SARS-CoV-2 infection presentation could range from asymptomatic to severe shortness of breath, lung fibrosis, multi-organ failure and eventually death of the patients (Holly et al., 2020; Zhu et al., 2020). The current study revealed that half of the hospitalized Jordanian patients were asymptomatic. This percentage of asymptomatic patients is higher than the previously reported prevalence of asymptomatic SARS-CoV-2 infection in a Korean sample (Kim et al., 2020). However, due to the study methodology of telephone interviews, survival bias could explain this higher asymptomatic prevalence in the current study cohort. On the other hand, the prevalence of asymptomatic cases in the current study is in line with reported 40 to $45 \%$ prevalence in Oran \& Topol review of the current literature (Oran and Topol, 2020).

The main finding of the current study was the significant association between increased BMI and longer COVID-19 symptoms in a group of Jordanian patients. A similar significant association was reported in a group of Kuwaiti patients where obesity was associated with significant poor COVID-19 outcomes (Al-Sabah et al., 2020). In addition, in five recent meta-analysis and review studies, a significant association between body weight and poor COVID-19 outcome were identified (Chang et al., correlation was identified between symptoms duration and male gender $(p$-value $=0.044)$. On the other hand, the correlation analysis failed to identify an association between the presence of comorbidities and symptoms duration, p-value 0.174 (Table 2).
2020; Cornejo-Pareja et al., 2020; Du et al., 2020; Malik et al., 2020; Peres et al., 2020). For example, RodríguezMolinero et al. revealed that obesity was an independent risk factor for poor COVID-19 prognosis in a group of Spanish patients (Rodríguez-Molinero et al., 2020). Similarly, Fresán et al reported that obesity was an independent risk factor for hospitalization and COVID-19 severity, especially in young patients; Peters et al. reported that obesity increase the odds for COVID-19 mortality for both genders (Fresán et al., 2020; Peters et al., 2020). Even though some studies identified increased BMI risk on COVID-19 poor outcome among certain groups, such as young people, women or people of black and Asian ethnic backgrounds, it seems that obesity is considered an independent risk factor for poor COVID-19 outcome across all patients groups, and even sometimes preceding the age as the main risk factor for poor prognosis of this novel infection (Caci et al., 2020; Fresán et al., 2020; Magdy Beshbishy et al., 2020; Moussa et al., 2020; Popkin et al., 2020).

The synergistic effects of overweight and obesity pandemic on COVID-19 pandemic made some researchers invent a new pandemic term, which is Covibesity, to emphasize the daring effects of these two pandemics when they interact with each other (Khan and Moverley Smith, 2020). In the current study, six out every ten COVID-19 confirmed cases in Jordan were obese or overweight. Currently, there is emerging evidence about the increased susceptibility of obese patients of acquired COVID-19 infection in community settings. However, this is an area that requires further investigation (Kimura and Namkoong, 2020).

The current cohort included seven patients who required an ICU admission after COVID-19 infection. This would limit the measurement of factors associated with ICU admission. However, it is not surprising that age was identified as an independent risk factor for ICU admission in the current study, after adjusting for other factors. Biscarini et al. conducted a larger study on Italian patients to explore the risks of ICU admission after COVID-19 infection, and they found that obesity was significantly associated with ICU admission after controlling for other variables (Biscarini et al., 2020). In addition, Popkin and colleagues revealed that obesity and overweight are both independent risk factors for ICU, IMV and mortality after SARS-CoV-2 infection (Popkin et al., 2020).

Although there is still not enough evidence about the efficacy of Hydroxychloroquine in COVID-19 management, from our medical records review, it seems 
that half of the hospitalized COVID-19 patients in Jordan were treated with Hydroxychloroquine (Table 1). This might require further review from health authorities about the need for applying and monitoring the local standard operating procedure (SOPs) in hospital settings (Das et al., 2020; Dragojevic Simic et al., 2020).

According to the current study findings, the average duration for COVID-19 symptoms was $13.1 \pm 6.8$ days. This is longer than Shah et al. findings, who reported a median duration of seven days in a cohort of American patients. However, Shah et al. study was conducted in an emergency department settings, while the current study was conducted in inpatients settings, and this could explain this difference in symptoms duration (Shah et al., 2020). On the other hand, Gupta et al. reported much shorter symptoms durations (two days), but their study sample was composed of only 21 Indian patients who were identified in February and March 2020 (Gupta et al., 2020). It seems that the focus of most COVID-19 studies is on mortality and severe outcomes, and there is a gap in the current literature about symptoms duration, especially in mild and moderate cases (Älgå et al., 2020).

The most common identified symptoms in this study were cough, loss of smell and loss of taste. This is slightly different from Kwok et al. findings who reported fever and cough as the most common symptoms of SARS-CoV-2 infection (Kwok et al., 2020). This difference in symptoms prevalence could be explained by the difference in study methodology, with recall biased of telephone interviews and with incomplete data documentation at the medical records.

In addition to BMI association with longer duration of COVID-19 symptoms, the current study revealed an independent significant association between gender and symptoms duration. Seidu and colleagues reported a similar association between male gender and poor COVID-19 outcome (Seidu et al., 2020). Several physiological and behavioral factors could explain this association such as the increased prevalence of tobacco product consumption between male patients, the effect of testosterone hormone and immune response differences (Howard, 2021; Salah and Mehta, 2020; Womersley et al., 2020).

Finally, the main limitations of the current study are the cross-sectional nature of the study, which does not allow for the measurement of causality between BMI and symptoms duration. In addition, this study was conducted with survivors of this novel infection; therefore, the survival bias cannot be avoided. Finally, the small sample size and having a sample from a single center in the capital city would limit the generalization of study results on the entire Jordanian population. Meanwhile, the main strength of this study is having a sample of both symptomatic and asymptomatic patients, in addition to collecting the data in a hybrid methodology that involved telephone interviews and medical records review. Lastly, the current study is one of the very first studies to explore the effects of SARS-CoV-2 infection on sample of patients of Arab ethnicity.

\section{Conclusions}

Increased BMI is significantly associated with more prolonged symptoms duration after SARS-CoV-2 infection. Likewise, the male gender was an independent significant factor associated with longer symptoms duration. The Jordanian authorities are advised to develop and share focused awareness messages for overweight and obese individuals so they can have strict social distancing and other prevention measures against COVID-19. Obese and overweight persons are a vulnerable group for this respiratory infection and they deserve advanced and tailored efforts to protect them from its adverse outcomes.

\section{Declaration of Interest}

No conflicting interests.

\section{References}

Ajlouni, K., Khader, Y., Batieha, A., Jaddou, H., El-Khateeb, M., 2020. An alarmingly high and increasing prevalence of obesity in Jordan. Epidemiol Health 42: e2020040.

Akour, A., Al-Tammemi, A.B., Barakat, M., Kanj, R., Fakhouri, H.N., Malkawi, A., Musleh, G., 2020. The Impact of the COVID19 Pandemic and Emergency Distance Teaching on the Psychological Status of University Teachers: A Cross-Sectional Study in Jordan. The American Journal of Tropical Medicine and Hygiene.

Älgå, A., Eriksson, O., Nordberg, M., 2020. Scientific Publications During the Early Phase of the COVID-19 Pandemic: A Topic Modeling Study. J Med Internet Res.

Al-Sabah, S., Al-Haddad, M., Al-Youha, S., Jamal, M., Almazeedi, S., 2020. COVID-19: Impact of obesity and diabetes on disease severity. Clin Obes.

Biscarini, S., Colaneri, M., Ludovisi, S., Seminari, E., Pieri, T.C., Valsecchi, P., Gallazzi, I., Giusti, E., Cammà, C., Zuccaro, V., Mondelli, M.U., 2020. The obesity paradox: Analysis from the SMAtteo COvid-19 REgistry (SMACORE) cohort. Nutrition, Metabolism and Cardiovascular Diseases 30: 1920-1925.

Blüher, M., 2019. Obesity: global epidemiology and pathogenesis. Nat Rev Endocrinol 15: 288-298.

Caci, G., Albini, A., Malerba, M., Noonan, D.M., Pochetti, P., Polosa, R., 2020. COVID-19 and Obesity: Dangerous Liaisons. JCM 9: 2511.

Caussy, C., Wallet, F., Laville, M., Disse, E., 2020. Obesity is Associated with Severe Forms of COVID-19. Obesity 28: 11751175.

Chang, T., Chou, C., Chang, L., 2020. Effect of obesity and body mass index on coronavirus disease 2019 severity: A systematic review and meta-analysis. Obesity Reviews 21 .

Cornejo-Pareja, I.M., Gómez-Pérez, A.M., Fernández-García, J.C., Barahona San Millan, R., Aguilera Luque, A., Hollanda, A., Jiménez, A., Jimenez-Murcia, S., Munguia, L., Ortega, E., Fernandez-Aranda, F., Fernández Real, J.M., Tinahones, F., 2020. Coronavirus disease 2019 and obesity. Impact of obesity and its main comorbidities in the evolution of the disease. Eur Eat Disorders Rev 28: 799-815.

Curtin, K.M., Pawloski, L.R., Mitchell, P., Dunbar, J., 2020. COVID-19 and Morbid Obesity: Associations and Consequences for Policy and Practice. World Medical \& Health Policy wmh3.361. 1

Cuthbertson, D.J., Alam, U., Tahrani, A., 2020. COVID-19 and obesity: an opportunity for change. Therapeutic Advances in Endocrinology 11: 204201882094974.

Das, R.R., Behera, B., Mishra, B., Naik, S.S., 2020. Effect of chloroquine and hydroxychloroquine on COVID-19 virological outcomes: An updated meta-analysis. Indian J Med Microbiol 38: 265-272. 
Dragojevic Simic, V., Miljkovic, M., Stamenkovic, D., Vekic, B., Ratkovic, N., Simic, R., Rancic, N., 2020. An overview of antiviral strategies for coronavirus 2 (SARS-CoV-2) infection with special reference to antimalarial drugs chloroquine and hydroxychloroquine. Int J Clin Pract e13825.

Du, Y., Lv, Y., Zha, W., Zhou, N., Hong, X., 2020. Association of Body mass index (BMI) with Critical COVID-19 and in-hospital Mortality: a dose-response meta-analysis. Metabolism 154373.

Dyett, J., 2020. Possible link between obesity and severe COVID-19. Medical Journal of Australia 213: 380.

Fedele, D., De Francesco, A., Riso, S., Collo, A., 2021. Obesity, malnutrition, and trace element deficiency in the coronavirus disease (COVID-19) pandemic: An overview. Nutrition 81: 111016.

Fresán, U., Guevara, M., Elía, F., Albéniz, E., Burgui, C., Castilla, J., Working Group for the Study of COVID-19 in Navarra, Martín, C., Navascués, A., Eugenia Portillo, M., Polo, I., Ezpeleta, C., Albéniz, E., Elía, F., Gorricho, J., Ardanaz, E., Ascunce, N., Arriazu, M., Barricarte, A., Barriuso, L., Burgui, C., Casado, I., Díaz, J., Ederra, M., Egüés, N., Fresán, U., Garde, C., Gómez-Ibáñez, C., García Cenoz, M., García, V., Guevara, M., Iriarte, N., Martínez-Baz, I., Moreno-Iribas, C., Sayón, C., Vidán, J., Castilla, J., 2020. Independent role of morbid obesity as a risk factor for COVID-19 hospitalization: a Spanish population-based cohort study. Obesity oby.23029.

Gunturiz Albarracín, M.L., Forero Torres, A.Y., 2020. Adiponectin and Leptin Adipocytokines in Metabolic Syndrome: What Is Its Importance? Dubai Diabetes Endocrinol J 26: 93-102. https://doi.org/10.1159/000510521

Gupta, N., Agrawal, S., Ish, P., Mishra, S., Gaind, R., Usha, G., Singh, B., Sen, M.K., Covid Working Group, S.H., 2020. Clinical and epidemiologic profile of the initial COVID-19 patients at a tertiary care centre in India. Monaldi Arch Chest Dis 90. https://doi.org/10.4081/monaldi.2020.1294

Hall, D.M.B., Cole, T.J., 2006. What use is the BMI? Arch Dis Child 91: 283-286.

Hijona Elósegui, J.J., Carballo García, A.L., Fernández Risquez, A.C., 2020. New evidences that discard the possible vertical transmission of SARS-CoV-2 during pregnancy. Medicina Clínica (English Edition) 155: 313-314.

Holly, J.M.P., Biernacka, K., Maskell, N., Perks, C.M., 2020. Obesity, Diabetes and COVID-19: An Infectious Disease Spreading From the East Collides With the Consequences of an Unhealthy Western Lifestyle. Front. Endocrinol. 11: 582870.

Howard, M.C., 2021. Gender, face mask perceptions, and face mask wearing: Are men being dangerous during the COVID-19 pandemic? Pers Individ Dif 170: 110417.

Huang, Y., Lu, Y., Huang, Y.-M., Wang, M., Ling, W., Sui, Y., Zhao, H.-L., 2020. Obesity in patients with COVID-19: a systematic review and meta-analysis. Metabolism 113: 154378.

Kang, Z., Luo, S., Gui, Y., Zhou, H., Zhang, Z., Tian, C., Zhou, Q., Wang, Q., Hu, Y., Fan, H., Hu, D., 2020. Obesity is a potential risk factor contributing to clinical manifestations of COVID-19. Int $\mathrm{J}$ Obes.

Khan, M.A., Moverley Smith, J.E., 2020. “Covibesity,” a new pandemic. Obesity Medicine 19: 100282.

Kim, G.-U., Kim, M.-J., Ra, S.H., Lee, J., Bae, S., Jung, J., Kim, S.-H., 2020. Clinical characteristics of asymptomatic and symptomatic patients with mild COVID-19. Clin Microbiol Infect 26: 948.e1-948.e3.

Kimura, T., Namkoong, H., 2020. Susceptibility of obese population to COVID-19. International Journal of Infectious Diseases.
Klatsky, A.L., Zhang, J., Udaltsova, N., Li, Y., Tran, H.N., 2017. Body Mass Index and Mortality in a Very Large Cohort: Is It Really Healthier to Be Overweight? Perm J 21: 16-142.

Kruglikov, I.L., Shah, M., Scherer, P.E., 2020. Obesity and diabetes as comorbidities for COVID-19: Underlying mechanisms and the role of viral-bacterial interactions. eLife 9: e61330.

Kwok, S., Adam, S., Ho, J.H., Iqbal, Z., Turkington, P., Razvi, S., Le Roux, C.W., Soran, H., Syed, A.A., 2020. Obesity: A critical risk factor in the COVID-19 pandemic. Clin Obes.

Liu, M., Deng, C., Yuan, P., Ma, J., Yu, P., Chen, J., Zhao, Y., Liu, X., 2020. Is there an exposure-effect relationship between body mass index and invasive mechanical ventilation, severity, and death in patients with COVID-19? Evidence from an updated meta-analysis. Obesity Reviews 21.

Lockhart, S.M., O’Rahilly, S., 2020. When Two Pandemics Meet: Why Is Obesity Associated with Increased COVID-19 Mortality? Med S2666634020300106.

Magdy Beshbishy, A., Hetta, H.F., Hussein, D.E., Saati, A.A., C. Uba, C., Rivero-Perez, N., Zaragoza-Bastida, A., Shah, M.A., Behl, T., Batiha, G.E.-S., 2020. Factors Associated with Increased Morbidity and Mortality of Obese and Overweight COVID-19 Patients. Biology 9: 280.

Malik, P., Patel, U., Patel, K., Martin, M., Shah, C., Mehta, D., Malik, F.A., Sharma, A., 2020. Obesity a predictor of outcomes of COVID-19 hospitalized patients-A systematic review and meta-analysis. J Med Virol jmv.26555.

Méry, G., Epaulard, O., Borel, A.-L., Toussaint, B., Le Gouellec, A., 2020. COVID-19: Underlying Adipokine Storm and Angiotensin 1-7 Umbrella. Front. Immunol. 11: 1714.

Michalakis, K., Panagiotou, G., Ilias, I., Pazaitou-Panayiotou, K., 2020. Obesity and COVID-19: A jigsaw puzzle with still missing pieces. Clin Obes.

Moussa, O., Zakeri, R., Arhi, C., O’Kane, M., Snowdon-Carr, V., Menon, V., Mahawar, K., Purkayastha, S., 2020. Impact of COVID-19 on Obesity Management Services in the United Kingdom (The COMS-UK study). OBES SURG.

Oran, D.P., Topol, E.J., 2020. Prevalence of Asymptomatic SARS-CoV-2 Infection: A Narrative Review. Ann Intern Med 173: 362-367.

Peres, K.C., Riera, R., Martimbianco, A.L.C., Ward, L.S., Cunha, L.L., 2020. Body Mass Index and Prognosis of COVID-19 Infection. A Systematic Review. Front. Endocrinol. 11: 562.

Peters, S.A.E., MacMahon, S., Woodward, M., 2020. Obesity as a risk factor for COVID-19 mortality in women and men in the UK biobank: Comparisons with influenza/pneumonia and coronary heart disease. Diabetes Obes Metab.

Popkin, B.M., Du, S., Green, W.D., Beck, M.A., Algaith, T., Herbst, C.H., Alsukait, R.F., Alluhidan, M., Alazemi, N., Shekar, M., 2020. Individuals with obesity and COVID-19: A global perspective on the epidemiology and biological relationships. Obesity Reviews 21.

Rancourt, R.C., Schellong, K., Plagemann, A., 2020. Coronavirus disease 2019 and obesity: one pandemic meets another. Am J Obstet Gynecol.

Ranjan, P., Kumar, A., Chowdhury, S., Pandey, S., Choudhary, A., Bhattacharya, A., Singh, A., Pandey, R.M., Wig, N., Vikram, N.K., 2020. Is excess weight a risk factor for the development of COVID 19 infection? A preliminary report from India. Diabetes \& Metabolic Syndrome: Clinical Research \& Reviews 14: 18051807.

Ravi, N., Cortade, D.L., Ng, E., Wang, S.X., 2020. Diagnostics for SARS-CoV-2 detection: A comprehensive review of the FDAEUA COVID-19 testing landscape. Biosens Bioelectron 165: 112454. 
Rodríguez-Molinero, A., Gálvez-Barrón, C., Miñarro, A., Macho, O., López, G.F., Robles, M.T., Dapena, M.D., Martínez, S., Milà Ràfols, N., Monaco, E.E., Hidalgo García, A., on behalf of the COVID-19 Research Group of CSAPG, 2020. Association between COVID-19 prognosis and disease presentation, comorbidities and chronic treatment of hospitalized patients. PLoS ONE 15: e0239571.

Salah, H.M., Mehta, J.L., 2020. Hypothesis: Sex-Related Differences in ACE2 Activity May Contribute to Higher Mortality in Men Versus Women With COVID-19. J Cardiovasc Pharmacol Ther 1074248420967792.

Samrah, S.M., Al-Mistarehi, A.-H., Aleshawi, A.J., Khasawneh, A.G., Momany, S.M., Momany, B.S., Abu Za'nouneh, F.J., Keelani, T., Alshorman, A., Khassawneh, B.Y., 2020a. Depression and Coping Among COVID-19-Infected Individuals After 10 Days of Mandatory in-Hospital Quarantine, Irbid, Jordan. Psychol Res Behav Manag 13: 823-830.

Samrah, S.M., Al-Mistarehi, A.-H.W., Ibnian, A.M., Raffee, L.A., Momany, S.M., Al-Ali, M., Hayajneh, W.A., Yusef, D.H., Awad, S.M., Khassawneh, B.Y., 2020b. COVID-19 outbreak in Jordan: Epidemiological features, clinical characteristics, and laboratory findings. Annals of Medicine and Surgery (2012) 57: 103-108.

Seidu, S., Gillies, C., Zaccardi, F., Kunutsor, S.K., Hartmann-Boyce, J., Yates, T., Singh, A.K., Davies, M.J., Khunti, K., 2020. The impact of obesity on severe disease and mortality in people with SARS-CoV-2: A systematic review and meta-analysis. Endocrinol Diab Metab.

Shah, S.J., Barish, P.N., Prasad, P.A., Kistler, A., Neff, N., Kamm, J., Li, L.M., Chiu, C.Y., Babik, J.M., Fang, M.C., AbeJones, Y., Alipanah, N., Alvarez, F.N., Botvinnik, O.B., Castaneda, G., CZB CLIAhub Consortium, Dadasovich, R.M., Davis, J., Deng, X., DeRisi, J.L., Detweiler, A.M., Federman, S., Haliburton, J., Hao, S., Kerkhoff, A.D., Kumar, G.R., Malcolm, K.B., Mann, S.A., Martinez, S., Mary, R.K., Mick, E., Mwakibete, L., Najafi, N., Peluso, M.J., Phelps, M., Pisco, A.O., Ratnasiri, K., Rubio, L.A., Sellas, A., Sherwood, K.D., Sheu, J., Spottiswoode, N., Tan, M., Yu, G., Kangelaris, K.N., Langelier, C., 2020. Clinical features, diagnostics, and outcomes of patients presenting with acute respiratory illness: A retrospective cohort study of patients with and without COVID-19. EClinicalMedicine 27: 100518.
Shaka, H., Raghavan, S., Trelles-Garcia, V.P., Trelles-Garcia, D., Abusalim, A.I., Parfieniuk, A., Ojemolon, P.E., Azubuike, C., 2020. Predicting COVID-19 Using Retrospective Data: Impact of Obesity on Outcomes of Adult Patients With Viral Pneumonia. Cureus.

Singh, S., Bilal, M., Pakhchanian, H., Raiker, R., Kochhar, G.S., Thompson, C.C., 2020. Impact of Obesity on Outcomes of Patients With Coronavirus Disease 2019 in the United States: A Multicenter Electronic Health Records Network Study. Gastroenterology S0016508520350678.

Smati, S., Tramunt, B., Wargny, M., Caussy, C., Gaborit, B., Vatier, C., Vergès, B., Ancelle, D., Amadou, C., Bachir, L.A., Bourron, O., Coffin-Boutreux, C., Barraud, S., Dorange, A., Fremy, B., Gautier, J., Germain, N., Larger, E., Laugier-Robiolle, S., Meyer, L., Monier, A., Moura, I., Potier, L., Sabbah, N., Seret-Bégué, D., Winiszewski, P., Pichelin, M., Saulnier, P., Hadjadj, S., Cariou, B., Gourdy, P., for the CORONADO investigators, 2020. Relationship between obesity and severe COVID-19 outcomes in patients with type 2 diabetes: Results from the CORONADO study. Diabetes Obes Metab dom.14228.

Soeroto, A.Y., Soetedjo, N.N., Purwiga, A., Santoso, P., Kulsum, I.D., Suryadinata, H., Ferdian, F., 2020. Effect of increased BMI and obesity on the outcome of COVID-19 adult patients: A systematic review and meta-analysis. Diabetes \& Metabolic Syndrome: Clinical Research \& Reviews 14: 1897-1904.

Womersley, K., Ripullone, K., Peters, S.A., Woodward, M., 2020. Covid-19: Male disadvantage highlights the importance of sex disaggregated data. BMJ m2870.

Zhu, Z., Hasegawa, K., Ma, B., Fujiogi, M., Camargo, C.A., Liang, L., 2020. Association of obesity and its genetic predisposition with the risk of severe COVID-19: Analysis of population-based cohort data. Metabolism 112: 154345. 